\title{
SMR
}

\section{Cross-species amplification and} polymorphism of microsatellite loci in Helicoverpa armigera and Helicoverpa zea (Lepidoptera: Noctuidae) in Brazilian cropping systems

\author{
N.A. Leite ${ }^{1}$, A.S. Corrêa ${ }^{2}$, A. Alves-Pereira ${ }^{3}$, J.B. Campos $^{3}$, M.I. Zucchi ${ }^{4}$ and C. Omoto ${ }^{1}$ \\ ${ }^{1}$ Laboratório de Resistência de Artrópodes a Pesticidas, \\ Departamento de Entomologia e Acarologia, \\ Escola Superior de Agricultura "Luiz de Queiroz", Universidade de São Paulo, \\ Piracicaba, SP, Brasil \\ ${ }^{2}$ Laboratório de Ecologia Molecular de Artrópodes, \\ Departamento de Entomologia e Acarologia, \\ Escola Superior de Agricultura "Luiz de Queiroz", Universidade de São Paulo, \\ Piracicaba, SP, Brasil \\ ${ }^{3}$ Laboratório de Diversidade Genética e Melhoramento, Departamento de Genética, \\ Escola Superior de Agricultura "Luiz de Queiroz", Universidade de São Paulo, \\ Piracicaba, SP, Brasil \\ ${ }^{4}$ Agência Paulista de Tecnologia dos Agronegócios, Piracicaba, SP, Brasil \\ Corresponding author: N.A. Leite \\ E-mail: alvesnat@gmail.com \\ Genet. Mol. Res. 15 (2): gmr.15027890 \\ Received October 22, 2015 \\ Accepted December 3, 2015 \\ Published April 4, 2016 \\ DOI http://dx.doi.org/10.4238/gmr.15027890
}

ABSTRACT. The Old World bollworm Helicoverpa armigera (Hübner) was recently discovered in Brazil. This species is closely related to the New World bollworm H. zea (Boddie), and mating between these species has already been reported under laboratory conditions. Here, we tested the cross-species amplification of 20 microsatellite (SSR) loci in field 
populations of $H$. armigera and $H$. zea collected from Brazilian cropping systems. Seven SSR loci were successfully amplified and polymorphic in both species except for the locus $\mathrm{HaC} 14$, which was monomorphic for $H$. zea. All SSR loci were in linkage equilibrium, and deviations from HardyWeinberg equilibrium were only observed for the locus HarSSR1 in the HaRS-2 population, where null alleles were present. A moderate level of polymorphism was detected in $H$. armigera and $H$. zea populations with a mean allele number of 4.14 , and 2.24 , respectively. Interestingly, most of the populations of the recent invader $\mathrm{H}$. armigera showed higher genetic diversity and inbreeding coefficients than $H$. zea populations. The genetic identity of each species was recovered using a STRUCTURE analysis, where the populations formed two clusters $(K=2)$ according to their species. STRUCTURE also suggested the occurrence of potential hybrid offspring between $H$. armigera and $H$. zea individuals in natural conditions. These SSR loci will be valuable in characterizing population differentiation, invasion routes, adaptation, reproductive behavior, and intra- and interspecific gene flow in $H$. armigera and $H$. zea populations in Brazil, the USA, and other areas where these two pests occur.

Key words: Helicoverpa; Microsatellite; Hybridization; Old World bollworm; Corn earworm; Invasive species

\section{INTRODUCTION}

A native of Oceania, the Old World bollworm, Helicoverpa armigera (Hübner), is one of the most severe agricultural pests in the world (Pogue, 2013). It has invaded several other continents, including Asia, Europe, and Africa, and was first reported in Brazil in 2013 (Czepak et al., 2013). This invasive pest rapidly spread throughout Brazil (Leite et al., 2014; Mastrangelo et al., 2014) and was also reported in other South American countries, such as Argentina (Múrua et al., 2014), Paraguay (Senave, 2014), Bolivia, and Uruguay (Czepak C, unpublished results). In 2015, it was found in Florida, USA (Hayden and Brambila, 2015), and now threatens crop production throughout the Americas.

Historically, the New World bollworm, $H$. zea (Boddie), is the most important species of the Helicoverpa genus in the Americas, including Brazil (Kogan et al., 1989). Although the exact evolutionary relationship between $H$. armigera and $H$. zea is uncertain, they are considered "twin" or "sibling" species, and are able to mate and produce fertile offspring under laboratory conditions (Laster and Hardee, 1995; Laster and Sheng, 1995; Cho et al., 2008, Pogue, 2013).

Both $H$. armigera and $H$. zea are highly polyphagous and have high reproductive and dispersal capacities that favor their rapid adaptation to various control tactics (e.g., insecticides and genetically modified plants) (Fitt, 1989; Head et al., 2010; Yang et al., 2013; Razmjou et al., 2014; Walsh et al., 2014). Due to the invasion of $H$. armigera, both species now coexist in Brazilian landscapes. Severe economic damage to different crops, such as cotton, millet, bean, sorghum, and soybean, has been reported in different regions of Brazil (Leite et al., 2014), which confirms the significant adaptation of $H$. armigera in Brazilian landscapes.

Population genetic studies of these two pests have been performed worldwide. Studies with mitochondrial and nuclear markers revealed high genetic diversity and low genetic structure (spatial, temporal, and host) (Endersby et al., 2007; Li et al., 2011; Perera and Blanco, 2011; Behere 
et al., 2007, 2013). Similar results have been observed in Brazil (Leite et al., 2014; Mastrangelo et al., 2014). However, in Brazil and other countries where both species occur, analyses with markers that evolve rapidly in the genome, such as microsatellites, are important in order to acquire information about intra- and interspecific gene flow between $H$. armigera and $H$. zea populations. This information is important to better understand the reproductive behavior, population structure, and potential hybridization events between $H$. armigera and $H$. zea.

Microsatellites or SSRs (simple sequence repeats) are polymorphic DNA loci that, in general, consist of one to six nucleotide sequences repeated in tandem. These are widespread and randomly dispersed in the genomes of all eukaryotic organisms (Litt and Luty, 1989; Tautz, 1989). SSR markers have been used in population genetic studies on Helicoverpa, owing to their higher informational content when compared to other types of molecular markers (Subramanian and Mohankumar, 2006; Perera and Blanco, 2011). Furthermore, SSR primers described for one species could be used to detect polymorphisms in other, closely related species, becoming useful tools in the detection of hybridization zones. Testing cross-species amplification of SSR is important to generate data more rapidly than by developing new SSR primers, and cheaper than using other new technologies (i.e., next-generation sequencing).

Grasela and McIntosh (2005) tested cross-species amplification of SSR markers developed for $H$. armigera on $H$. zea populations from the USA, generating only four loci that lead to amplification in both species. SSR markers developed for $H$. zea (Perera et al., 2007) were never tested in $H$. armigera. Thus, our main objectives were to i) test the cross-amplification of 13 microsatellite loci previously characterized from $H$. zea in $H$. armigera, ii) retest for the crossamplification of seven microsatellite loci from $H$. armigera (Scott et al., 2004; Ji et al., 2003, 2005) in $H$. zea, in order to determine whether they also work in Brazilian populations, and iii) characterize the polymorphism of these microsatellites and develop a set of polymorphic markers available to researchers for investigations of genetic diversity and mating systems of these species in Brazil. Ultimately, our aim in this paper was a preliminary evaluation of the usefulness of these markers on the detection of potential hybrids in a few Brazilian populations of $H$. armigera and $H$. zea.

\section{MATERIAL AND METHODS}

\section{Sampling and DNA extraction}

Sixty-four $H$. armigera larvae and $72 H$. zea larvae were collected at six sampling sites (Table 1 and Figure 1). Helicoverpa spp larvae were maintained on an artificial diet modified from that used by Greene et al. (1976), in which white beans were used under controlled laboratory conditions, at $25^{\circ} \pm 1^{\circ} \mathrm{C}, 60 \pm 10 \%$ relative humidity, and $14: 10$-h light/dark photoperiod. After adult emergence, genomic DNA was isolated from the thorax of each individual using an Invisorb Spin Tissue Kit (STRATEC Molecular, Berlin, Germany), according to the manufacturer protocol. Species identification was confirmed using a method based on interspecific polymorphisms in the cytochrome c oxidase subunit I (COI) gene as described by Behere et al. (2008).

\section{Microsatellite cross-species amplification}

Thirteen pairs of microsatellite primers described for $H$. zea were tested in $H$. armigera, and seven pairs of microsatellite primers described for $H$. armigera were tested in $H$. zea (Table 2). The forward primers were modified with the addition of the M13 forward sequence 
(5'-CACGACGTTGTAAAACGAC-3') at the 5'-end. PCR amplification was performed in a 10- $\mu \mathrm{L}$ reaction mixture containing $0.5 \mu \mathrm{M}$ each primer, $2.5 \mathrm{mM} \mathrm{dNTP}, 3.75 \mathrm{mM} \mathrm{MgCl}, 0.5 \mu \mathrm{L} \mathrm{BSA}_{2}(2.5$ $\mathrm{mg} / \mathrm{mL}$ ), $0.25 \mathrm{pmol}$ M13 forward primer (modified with IRDye 700 or IRDye 800 fluorescence), 10\% 10X Taq Buffer, 1 U Taq DNA polymerase (Life Technologies, Carlsbad, CA, USA), and 50 ng genomic DNA. PCR amplifications proceeded according to the following protocol: $95^{\circ} \mathrm{C}$ for $5 \mathrm{~min}$ followed by 30 cycles at $95^{\circ} \mathrm{C}$ for $45 \mathrm{~s}$; different annealing temperatures $\left({ }^{\circ} \mathrm{C}\right)$ for each locus/species for $45 \mathrm{~s}$; and $72^{\circ} \mathrm{C}$ for $45 \mathrm{~s}$. For the $\mathrm{M} 13$ reactions, the 30 cycles were immediately followed by eight cycles at $94^{\circ} \mathrm{C}$ for $45 \mathrm{~s}, 53^{\circ} \mathrm{C}$ for $45 \mathrm{~s}$, and $72^{\circ} \mathrm{C}$ for $45 \mathrm{~s}$, with a final extension at $72^{\circ} \mathrm{C}$ for $10 \mathrm{~min}$. Amplified fragments were visualized on $2 \%(\mathrm{w} / \mathrm{v})$ agarose gels with a 1-kb DNA ladder. After PCR optimization, the loci that showed clear and robust band amplification on the agarose gels were selected for polymorphism analysis. The amplification products were separated under denaturing conditions on $5 \%(\mathrm{v} / \mathrm{v})$ polyacrylamide gels containing $8 \mathrm{M}$ urea and $1 \mathrm{X}$ TBE $(0.045 \mathrm{M}$ Tris-borate and $1 \mathrm{mM}$ EDTA) in a semi-automated DNA sequencer (LI-COR 4300S DNA Analysis System; LICOR Biosciences, Lincoln, NE, USA) for approximately $2 \mathrm{~h}$ at $70 \mathrm{~W}$. The loci were genotyped using the Saga software (LI-COR Biosciences).

Table 1. Identification code, location, collection site (crop), date of collection of Helicoverpa armigera and $\mathrm{H}$. zea populations, and number of individuals $(\mathrm{N})$ used in the cross-amplification test with the 20 microsatellite loci previously published.

\begin{tabular}{|c|c|c|c|c|c|c|}
\hline Population code & City, State & Crop & Latitude & Longitude & Date & $\mathrm{N}$ \\
\hline \multicolumn{7}{|l|}{ H. armigera } \\
\hline HaGO-2 & Mineiros, GO & Soybean & $17^{\circ} 34^{\prime} 10^{\prime \prime} \mathrm{S}$ & $52^{\circ} 33^{\prime} 04^{\prime \prime} \mathrm{W}$ & Jan. 2014 & 24 \\
\hline HaBA-44 & Luís Eduardo Magalhães, BA & Cotton & $12^{\circ} 05^{\prime} 58^{\prime \prime} \mathrm{S}$ & $45^{\circ} 47^{\prime} 54^{\prime \prime} \mathrm{W}$ & Feb. 2014 & 23 \\
\hline HaRS-2 & Itaara, RS & Soybean & $29^{\circ} 36^{\prime} 35^{\prime \prime} \mathrm{S}$ & $53^{\circ} 45^{\prime} 53^{\prime \prime} \mathrm{W}$ & Mar. 2014 & 17 \\
\hline \multicolumn{7}{|l|}{ H. zea } \\
\hline HzBA-32 & Luís Eduardo Magalhães, BA & Maize & $12^{\circ} 05^{\prime} 58^{\prime \prime} \mathrm{S}$ & $45^{\circ} 47^{\prime} 54^{\prime \prime} \mathrm{W}$ & Jun. 2013 & 24 \\
\hline HzMG-4 & Capitólio, MG & Maize & $20^{\circ} 36^{\prime} 17^{\prime \prime S}$ & $46^{\circ} 04^{\prime} 19^{\prime \prime} \mathrm{W}$ & Feb. 2014 & 24 \\
\hline $\mathrm{HzSP}-13$ & Cândido Mota, SP & Maize & $22^{\circ} 44^{\prime} 46^{\prime \prime} \mathrm{S}$ & $50^{\circ} 23^{\prime} 15^{\prime \prime} \mathrm{W}$ & Mar. 2014 & 24 \\
\hline
\end{tabular}

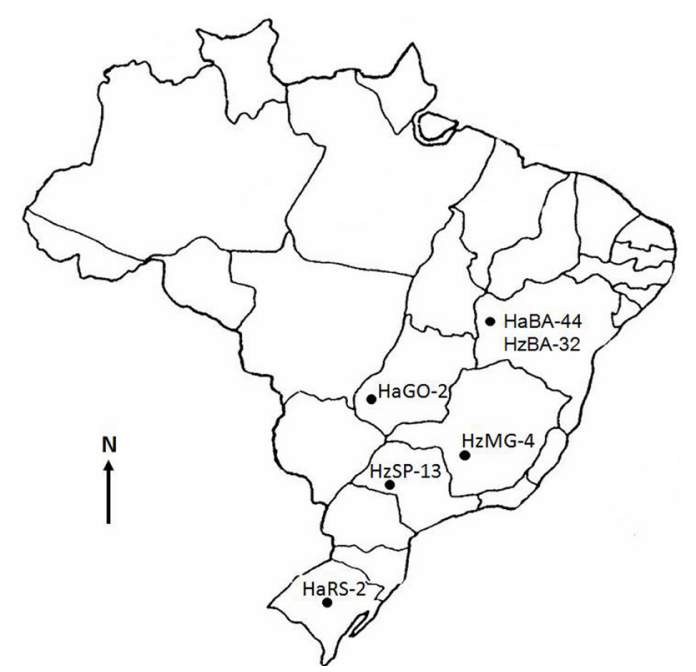

Figure 1. Distribution of Helicoverpa armigera (HaBA-44, HaGO-2, and HaRS-2) and H. zea (HzMG-4, HzSP-13, and HzBA-32) populations sampled in Brazil. 
Table 2. Characteristics of 20 microsatellite loci previously published for Helicoverpa zea and $H$. armigera.

\begin{tabular}{|c|c|c|c|c|}
\hline Locus & Primer sequence $\left(5^{\prime}-3^{\prime}\right)$ & $\begin{array}{c}\text { Repeat } \\
\text { motif }\end{array}$ & $\begin{array}{l}\text { Allele size and } \\
\text { size range } \\
\text { (bp) }\end{array}$ & Reference \\
\hline HzMS1-4 & $\begin{array}{l}\text { F: CAAGTGATAAAAGACGCCGAAGAT } \\
\text { R: TTGATCGTCAAGGAAGTGGCTAT }\end{array}$ & $(\text { TGA })_{6}$ & $118(111-144)$ & $\begin{array}{l}\text { Perera et al. }(2007)^{2} \\
\end{array}$ \\
\hline HzMS1-6 & $\begin{array}{l}\text { F: GTTTTGTCATTTGTCAAGCCGAA } \\
\text { R: AGCTCCCATACAACAAACGTGATT }\end{array}$ & $(\mathrm{TGA})_{7}$ & $237(208-245)$ & Perera et al. (2007) \\
\hline HzMS3-1 & $\begin{array}{l}\text { F: CAGTAGTTCCTGAGATTAGCGCGT } \\
\text { R: ATCACGTTCTCGAAAAACATTGCT }\end{array}$ & $(\mathrm{CAAA})_{4}$ & $113(106-110)$ & Perera et al. (2007) \\
\hline HzMS3-4 & $\begin{array}{l}\text { F: GGTCAAGATTCGTGCCGATAACTA } \\
\text { R: TTTTCGGTTCAGTGGCTTGTAGTAG }\end{array}$ & $(\text { TCTG })_{4}$ & $118(115-117)$ & Perera et al. (2007) \\
\hline HzMS3-11 & $\begin{array}{l}\text { F: ACTTCAAAGTTCGATTCTTGGGAT } \\
\text { R: GCTCAAAGAGGACTACGTAGCTGA }\end{array}$ & $(\mathrm{AGCT})_{4}$ & $106(93-106)$ & Perera et al. (2007) \\
\hline HzMS3-41 & $\begin{array}{l}\text { F: AAATTTCAACCAAATCGGTCTAGC } \\
\text { R: TGGCCGAACTATAATATCTTACTTCCTA }\end{array}$ & $(\mathrm{ACAT})_{4}$ & $121(121-135)$ & Perera et al. (2007) \\
\hline HzMS3-48 & $\begin{array}{l}\text { F: GGTGAAATGGAAATTGTTATCTATCCC } \\
\text { R: TCAGTCCAGTGGTTTAGACGTGAA }\end{array}$ & $(\mathrm{TCTG})_{4}$ & $101(94-102)$ & Perera et al. (2007) \\
\hline HzMS3-86 & $\begin{array}{l}\text { F: GGGGAAAAGAGGAAACAAATCATC } \\
\text { R: GAAACACGTTTGAGGAGGTCAGAT }\end{array}$ & $(\mathrm{CAT})_{4}$ & $140(136-151)$ & Perera et al. (2007) \\
\hline HzMS4-3 & $\begin{array}{l}\text { F: ACTTTCCGCATCCGATTAAAATGT } \\
\text { R: CAAATCGGACCAGTAGTTCCTGAG }\end{array}$ & $(\mathrm{GTTT})_{4}$ & $122(122-126)$ & Perera et al. (2007) \\
\hline HzMS4-10 & $\begin{array}{l}\text { F: CTAGAACGGGCTTCATGGTGAG } \\
\text { R: AAAAATAAAATGTATTCCGGGCGT }\end{array}$ & $(\text { ATT })_{4}$ & $113(110-113)$ & Perera et al. (2007) \\
\hline HzMS4-14 & $\begin{array}{l}\text { F: CAACATACAACATTCAGCCTGTCC } \\
\text { R: TCAGTCGTCAGTTTTTGTCTTTGC }\end{array}$ & $(\mathrm{AC})_{7}$ & $132(110-135)$ & Perera et al. (2007) \\
\hline HzMS4-16 & $\begin{array}{l}\text { F: AGTGTATACGGAGCAAGAATTGGA } \\
\text { R: TTTTGCAAATCAAACTATTGAAAAGTAA }\end{array}$ & $(\text { ACAT })_{6}$ & 147 (134-149) & Perera et al. (2007) \\
\hline HzMS4-23 & $\begin{array}{l}\text { F: GTTCAGCGGTTTAGATGTGAAAGG } \\
\text { R: TAAGGGTTCGTGTAGAAGTTCCCA }\end{array}$ & $(\mathrm{GACA})_{4}$ & $135(130-139)$ & Perera et al. (2007) \\
\hline $\mathrm{HaB60}$ & $\begin{array}{l}\text { F: CACCACCTGACATAACGC } \\
\text { R: AAGGAGCAGCAATTGCAAGC }\end{array}$ & $(\mathrm{CTG})_{2}(\mathrm{TTG})_{3}(\mathrm{CTG})_{5}(\mathrm{TTG})_{2}$ & $162^{1}$ & Scott et al. $(2004)^{\mathrm{a}}$ \\
\hline $\mathrm{HaC} 87$ & $\begin{array}{l}\text { F: ACGCGAGCACCAACTGTAA } \\
\text { R: GAGACCAATAGCAGTAGTTC }\end{array}$ & $(\mathrm{TC})_{5}$ & $118^{1}$ & Scott et al. (2004) \\
\hline HaC14 & $\begin{array}{l}\text { F: TCCACACAGTTTGCATTATGA } \\
\text { R: CGCCATAATCCTATTGATTC }\end{array}$ & $(\text { ATTT })_{5}$ & $161^{1}$ & Scott et al. (2004) \\
\hline HarSSR1 & $\begin{array}{l}\text { F: TAGGTGATTGTGGCTCAGTTTT } \\
\text { R: CAAACCCATCAGCAAATGCAAC }\end{array}$ & $\begin{array}{c}(\mathrm{TGC})_{2} \mathrm{GAT}(\mathrm{TGY})_{4} \mathrm{GAT} \\
(\mathrm{TGY})_{35}(\mathrm{TGA})_{2} \text { AGC }(\text { TGY })_{8}\end{array}$ & 240 (228-288) & Ji et al. $(2003)^{a}$ \\
\hline HarSSR6 & $\begin{array}{l}\text { F: TGTTGTTGCAGAGCTGCC } \\
\text { R: TTCAGCAACACAACCGTACA }\end{array}$ & $(\mathrm{GHT})_{43}$ & $(292-340)^{1}$ & Ji et al. $(2005)^{\mathrm{a}}$ \\
\hline HarSSR7 & $\begin{array}{l}\text { F: AAGCAATAATTACCAGAAACAG } \\
\text { R: GTTTATTCGTGTATTCATTAAATAG }\end{array}$ & $(\mathrm{GAT})_{4}$ & $(80-176)^{1}$ & Ji et al. (2005) \\
\hline HarSSR9 & $\begin{array}{l}\text { F: AGCTCCACAACTCTTAACTAC } \\
\text { R: GCAAACGATCACTGATATTAAC }\end{array}$ & $(\mathrm{CA})_{15}$ & $(189-261)^{1}$ & Ji et al. (2005) \\
\hline
\end{tabular}

${ }^{1}$ No further information provided. ${ }^{2}$ Helicoverpa zea. ${ }^{a}$ Helicoverpa armigera.

\section{Population genetic statistics}

To estimate polymorphism, allele frequencies, species-specific alleles (private alleles), expected and observed heterozygosities, and the inbreeding coefficient (f), we used the GDA software (Lewis and Zaykin, 2001). Hardy-Weinberg equilibrium (HWE) and linkage disequilibrium were tested using the FSTAT software (Goudet, 2002). The significance of each test was assessed based on 20,000 permutations, and a Bonferroni correction was used to correct for multiple testing (Weir, 1996). The nullallele frequency was estimated using the program FreeNA (Chapuis and Estoup, 2007).

To detect the possible presence of hybrids within Helicoverpa spp populations in Brazil, Bayesian assignment tests were performed using STRUCTURE v. 2.3.3 (Pritchard et al., 2000). This software uses a Bayesian approach based on a Markov chain Monte Carlo (MCMC) algorithm, which divides individuals within "K" clusters (i.e., populations) in which the HWE is maximized and the linkage disequilibrium is minimized. Ten independent runs were performed with a 100,000 
burn-in period followed by 500,000 MCMC steps. The K number for simulations ranged from 1 to 9 , as suggested by Evanno et al. (2005). The consensus values for $\mathrm{K}$ were obtained with CLUMPP v. 1.1.2 (Jakobsson and Rosenberg, 2007). The best $\mathrm{K}$ was recognized according to the $\Delta \mathrm{K}$ method of Evanno et al. (2005), as calculated with the web application Structure Harvester (Earl and vonHoldt, 2012).

\section{RESULTS}

\section{Microsatellite cross-species amplification}

Among the 13 SSR loci previously published for $H$. zea, the loci HzMS1-4, HzMS3-11 and HzMS3-41 were successfully amplified and evaluated in $H$. armigera (Table 3). Primers HzMS1-6, HzMS3-1, and HzMS4-3 failed to consistently amplify in all $H$. armigera samples, even at various annealing temperatures. Primers HzMS3-48, HzMS3-86, HzMS4-10, HzMS4-14, HzMS4-16, and HzMS4-23 amplified, but were non-specific, showing multiple bands during electrophoresis. For $H$. zea, the loci HaB60, HaC87, HaC14, and HarSSR1 were successfully amplified. The other three loci, HarSSR6, HarSSR7, and HarSSR9, did not amplify. All cross-amplified loci were polymorphic within both species with the exception of locus $\mathrm{HaC} 14$, which was monomorphic for $H$. zea. The most polymorphic locus was HasSSR1, which showed 12 alleles in $H$. armigera and five alleles in $H$. zea. Overall, the number of alleles varied from three (HzMS3-41 and HaC87 loci) to 12 for $H$. armigera with a mean number of 4.142 and from one (HaC14 locus) to five in $H$. zea with a mean number of 2.238 (Tables 3 and 4). $H$. armigera showed 16 species-specific alleles, while $H$. zea showed two species-specific alleles (Table 2). The allele sizes were similar to those reported from the authors that developed the primers, matching the expected repeat sizes (Tables 2 and 3).

Table 3. Locus name, annealing temperature (Ta), number of alleles, allele size and amplitude, and private alleles for both species of the seven microsatellite loci in Helicoverpa armigera and $H$. zea populations.

\begin{tabular}{|c|c|c|c|c|c|c|}
\hline \multirow{2}{*}{ Locus } & \multirow{2}{*}{$\mathrm{Ta}\left({ }^{\circ} \mathrm{C}\right)$} & \multicolumn{2}{|r|}{ H. armigera $(\mathrm{N}=64)^{1}$} & \multicolumn{2}{|c|}{ H. zea $(\mathrm{N}=72)^{1}$} & \multirow{2}{*}{$\begin{array}{l}\text { Allele size and } \\
\text { size range (bp) }\end{array}$} \\
\hline & & $\begin{array}{l}\text { No. of } \\
\text { alleles }\end{array}$ & Alleles & $\begin{array}{l}\text { No. of } \\
\text { alleles }\end{array}$ & Alleles & \\
\hline HzMS1-4 & 60 & 4 & $113,116,119,122$ & 3 & $116,119,122$ & $116(113-122)$ \\
\hline HzMS3-11 & 60 & 4 & $98,102,106,110$ & 3 & $98,106,110$ & $110(98-110)$ \\
\hline HzMS3-41 & 60 & 3 & $121,125,129$ & 3 & $121,125,129$ & $121(121-129)$ \\
\hline $\mathrm{HaB60}$ & 55 & 4 & 164, 167, 170, 173 & 4 & 161, 167, 170, 173 & $167(161-173)$ \\
\hline $\mathrm{HaC87}$ & 50 & 3 & $110,114,118$ & 2 & 110,118 & $110(110-118)$ \\
\hline $\mathrm{HaC} 14$ & 55 & 6 & $142,150,154,158,162,166$ & 1 & 158 & $158(142-166)$ \\
\hline HarSSR1 & 58 & 12 & $\begin{array}{c}242,248,251,254,257, \mathbf{2 6 0}, \mathbf{2 6 3} \\
266,269,275,284,287\end{array}$ & 5 & $\begin{array}{c}242,245,248,254 \\
257\end{array}$ & $242(242-287)$ \\
\hline
\end{tabular}

${ }^{1}$ Number of individuals evaluated. Highlighted in bold are the species-specific alleles.

\section{Population genetic statistics}

There was no linkage disequilibrium for any locus combination, and all populations showed $\mathrm{P}$ values higher than 0.00238 (FSTAT corrected $\mathrm{P}$ value). Null alleles were detected in all $H$. armigera populations at the HaC14 locus, in two populations (HaBA-44 and HaRS-2) at the HaC87 locus, and in the HaRS-2 population at the HarSSR1 locus (Table 4). Within H. zea, null alleles were only detected for the population HzBA-32 at the HaC87 locus. Despite the presence of null alleles, the tests of HWE showed that all populations and all loci were in equilibrium, except for population HaRS-2 with the locus HarSSR1 ( $P \leq 0.00238$; Table 4). 


\begin{tabular}{|c|c|c|c|c|c|c|c|c|c|}
\hline Population & $\begin{array}{c}\text { Diversity } \\
\text { indices }\end{array}$ & HzMS1-4 & $\begin{array}{c}\text { HzMS3- } \\
11\end{array}$ & $\begin{array}{c}\text { HzMS3- } \\
41\end{array}$ & $\mathrm{HaB} 60$ & $\mathrm{HaC} 87$ & $\mathrm{HaC} 14$ & HarSSR1 & Mean \\
\hline \multirow{5}{*}{ HaBA-44 } & $N_{\mathrm{A}}$ & 3.000 & 2.000 & 3.000 & 3.000 & 3.000 & 3.000 & 11.000 & 4.000 \\
\hline & $H_{E}$ & 0.298 & 0.359 & 0.554 & 0.236 & 0.152 & 0.573 & 0.879 & 0.436 \\
\hline & $H_{0}$ & 0.238 & 0.363 & 0.857 & 0.260 & 0.052 & 0.350 & 0.739 & 0.408 \\
\hline & $f$ & 0.206 & -0.012 & -0.568 & -0.104 & 0.660 & 0.395 & 0.162 & 0.064 \\
\hline & $a$ & 0.067 & 0.000 & 0.000 & 0.000 & 0.137 & 0.141 & 0.055 & \\
\hline \multirow{5}{*}{ HaGO-2 } & $N_{\mathrm{A}}$ & 4.000 & 3.000 & 3.000 & 4.000 & 2.000 & 5.000 & 12.000 & 4.714 \\
\hline & $H_{E}$ & 0.354 & 0.507 & 0.219 & 0.373 & 0.047 & 0.730 & 0.871 & 0.443 \\
\hline & $\mathrm{Ho}_{\mathrm{O}}$ & 0.409 & 0.388 & 0.238 & 0.347 & 0.047 & 0.500 & 0.695 & 0.375 \\
\hline & $f$ & -0.159 & 0.239 & -0.086 & 0.071 & 0.000 & 0.320 & 0.205 & 0.157 \\
\hline & $a$ & 0.000 & 0.084 & 0.000 & 0.024 & 0.000 & 0.137 & 0.091 & \\
\hline \multirow{5}{*}{ HaRS-2 } & $N_{A}$ & 3.000 & 4.000 & 2.000 & 4.000 & 2.000 & 4.000 & 7.000 & 3.714 \\
\hline & $H_{E}$ & 0.301 & 0.333 & 0.370 & 0.477 & 0.239 & 0.777 & 0.847 & 0.478 \\
\hline & $\mathrm{Ho}_{\mathrm{O}}$ & 0.333 & 0.272 & 0.470 & 0.625 & 0.000 & 0.444 & $0.416^{*}$ & 0.366 \\
\hline & $f$ & -0.111 & 0.189 & -0.280 & -0.321 & 1.000 & 0.443 & 0.519 & 0.239 \\
\hline & $a$ & 0.000 & 0.000 & 0.000 & 0.000 & 0.230 & 0.171 & 0.227 & \\
\hline \multirow{4}{*}{$\begin{array}{l}H \text {. armigera } \\
\text { mean }\end{array}$} & $N_{A}$ & 3.333 & 3.000 & 2.666 & 3.666 & 2.333 & 4.000 & 10.000 & 4.142 \\
\hline & $H_{\mathrm{E}}$ & 0.317 & 0.411 & 0.406 & 0.359 & 0.138 & 0.689 & 0.876 & 0.452 \\
\hline & $\mathrm{Ho}_{\mathrm{O}}$ & 0.327 & 0.352 & 0.525 & 0.387 & 0.036 & 0.431 & 0.655 & 0.383 \\
\hline & $f$ & -0.033 & 0.143 & -0.296 & -0.078 & 0.739 & 0.376 & 0.254 & 0.155 \\
\hline \multirow{5}{*}{ HzMG-4 } & $N_{A}$ & 3.000 & 2.000 & 2.000 & 2.000 & 1.000 & 1.000 & 4.000 & 2.143 \\
\hline & $H_{E}$ & 0.327 & 0.500 & 0.130 & 0.130 & 0.000 & 0.000 & 0.233 & 0.188 \\
\hline & $\mathrm{Ho}_{\mathrm{O}}$ & 0.291 & 0.421 & 0.136 & 0.136 & 0.000 & 0.000 & 0.250 & 0.176 \\
\hline & $f$ & 0.110 & 0.162 & -0.050 & -0.050 & 0.000 & 0.000 & -0.073 & 0.066 \\
\hline & $a$ & 0.036 & 0.045 & 0.000 & 0.000 & 0.001 & 0.001 & 0.000 & \\
\hline \multirow{5}{*}{ HzSP-13 } & $N_{A}$ & 3.000 & 2.000 & 2.000 & 2.000 & 1.000 & 1.000 & 4.000 & 2.143 \\
\hline & $H_{E}$ & 0.121 & 0.493 & 0.241 & 0.043 & 0.000 & 0.000 & 0.335 & 0.176 \\
\hline & $H_{0}$ & 0.125 & 0.523 & 0.272 & 0.043 & 0.000 & 0.000 & 0.291 & 0.179 \\
\hline & $f$ & -0.029 & -0.064 & -0.135 & 0.000 & 0.000 & 0.000 & 0.132 & -0.018 \\
\hline & $a$ & 0.000 & 0.000 & 0.000 & 0.000 & 0.001 & 0.001 & 0.060 & \\
\hline \multirow{5}{*}{ HzBA-32 } & $N_{\mathrm{A}}$ & 2.000 & 3.000 & 3.000 & 3.000 & 2.000 & 1.000 & 3.000 & 2.429 \\
\hline & $H_{E}$ & 0.042 & 0.565 & 0.449 & 0.138 & 0.085 & 0.000 & 0.510 & 0.256 \\
\hline & $\mathrm{Ho}_{\mathrm{O}}$ & 0.042 & 0.500 & 0.590 & 0.142 & 0.000 & 0.000 & 0.608 & 0.269 \\
\hline & $f$ & 0.000 & 0.118 & -0.325 & -0.034 & 1.000 & 0.000 & -0.198 & -0.053 \\
\hline & $a$ & 0.000 & 0.093 & 0.000 & 0.000 & 0.139 & 0.001 & 0.000 & \\
\hline \multirow{4}{*}{$\begin{array}{l}\text { H. zea } \\
\text { mean }\end{array}$} & $N_{A}$ & 2.666 & 2.666 & 2.333 & 2.333 & 1.333 & 1.000 & 3.666 & 2.238 \\
\hline & $H_{E}$ & 0.163 & 0.519 & 0.273 & 0.103 & 0.028 & 0.000 & 0.359 & 0.207 \\
\hline & $\mathrm{Ho}_{\mathrm{O}}$ & 0.153 & 0.481 & 0.333 & 0.107 & 0.000 & 0.000 & 0.383 & 0.208 \\
\hline & $f$ & 0.066 & 0.075 & -0.225 & -0.036 & 1.000 & 0.000 & -0.068 & -0.007 \\
\hline
\end{tabular}

$N_{\mathrm{A}}$, number of alleles; $H_{\mathrm{E}}$, expected heterozygosity; $H_{\mathrm{O}}$, observed heterozygosity; $f$, inbreeding coefficient; $a$, null alleles. Significant values are highlighted in bold. Deviation from HWE: ${ }^{*} \mathrm{P} \leq 0.0024$. 
$H$. armigera showed an average heterozygosity (expected/observed) of $0.452 / 0.383$, varying from $0.436 / 0.408$ in population HaBA-44 to $0.478 / 0.366$ in population HaRS-2. The average $f$ was 0.155 , varying from 0.064 (population HaBA-44) to 0.239 (population HaRS-2) (Table 4). For $H$. zea, the average heterozygosity was $0.207 / 0.208$, varying from $0.176 / 0.179$ in population $\mathrm{HzSP}-13$ to $0.256 / 0.269$ in population HzBA-32. The $f$ varied from -0.053 (population HzBA-32) to 0.066 (population HzMG-4) with an average of -0.007 (Table 4). Furthermore, most of the loci in the $H$. armigera populations showed higher values of observed heterozygosity than in the $H$. zea populations, except for the HzMS3-11 locus.

The STRUCTURE analysis indicated that the best $K$ when $H$. armigera and $H$. zea individuals were analyzed jointly was $K=2$ (Figure 2). The individuals were divided into two genetic clusters according to their respective species (Figure 3). In the $H$. armigera cluster there were nine individuals with greater similarity (>0.50 assignment) to $H$. zea individuals; the same occurred with one individual of the H. zea cluster (Figure 3).

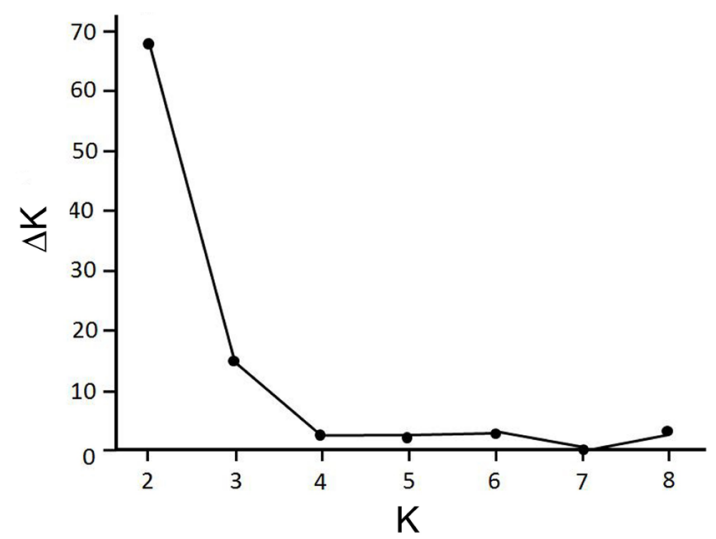

Figure 2. Graphical plot of $\Delta K$ for Helicoverpa armigera and $H$. zea; the maximum value of $\Delta K$ was considered to be the value of $K$ (genetic groups or clusters) that best fit the data; $K=2$.

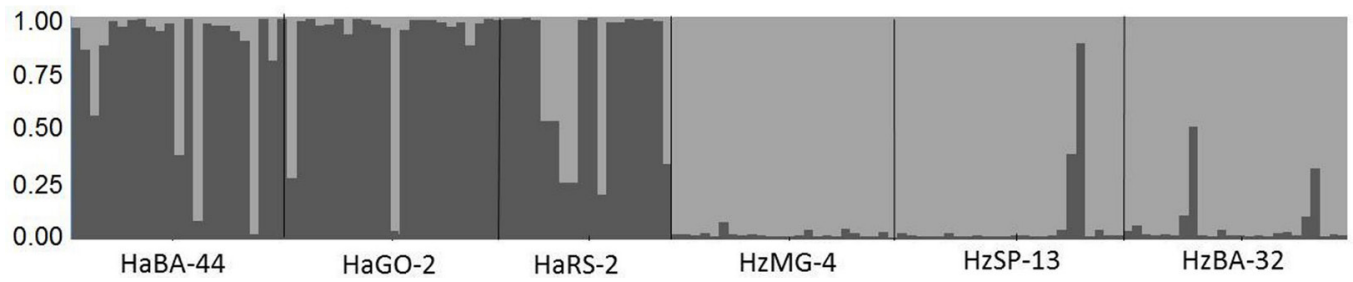

Figure 3. Bar plot for $K=2$ clusters for Helicoverpa armigera (HaBA-44, HaGO-2, and HaRS-2) and H. zea (HzMG-4, HzSP-13, and HzBA-32) individuals assigned by STRUCTURE, based on seven microsatellite loci. Each color (dark and light gray) represents a different cluster.

\section{DISCUSSION}

Cross-species amplification tests of SSR loci is an important and rapid method to generate informative markers, even for species for which microsatellites have not yet been characterized. The alternative is the development of species-specific SSR markers, which may be costly and 
take a long time to develop. For invasive species, using previously developed microsatellites from related species can generate data quickly to establish patterns of migration and gene flow as well as detect potential hybridization. Seven loci were successfully cross-amplified in $H$. armigera and $H$. zea and can be useful to further understand the invasion routes, gene flow, population structure, and mating systems of both species. Furthermore, the detection of cross-species SSR markers is extremely important for population studies in areas where $H$. armigera and $H$. zea individuals occur in sympatry, which can result in interspecific gene flow (by hybridization) between natural populations of these species (Laster and Hardee, 1995; Laster and Sheng, 1995).

The cross-species amplification success of SSR primers between $\mathrm{H}$. armigera and $\mathrm{H}$. zea was low. Only three of the 13 primers previously described for $H$. zea were successfully crossamplified in $\mathrm{H}$. armigera. Among the primers that we retested, the same four of the seven primers described for $H$. armigera were successfully cross-amplified in $H$. zea. This is consistent with the results of previous cross-amplification tests of 14 SSR primers described for $\mathrm{H}$. armigera in $\mathrm{H}$. zea (Grasela and Mclntosh, 2005), where the same four loci were amplified. This confirms the low cross-amplification success of SSR primers between the two species. These results suggest the rapid evolution of some primer biding sites in both species' genomes. This genetic divergence between the species is a paradox because they are able to produce fertile hybrid offspring in the laboratory (Laster and Hardee, 1995; Laster and Sheng, 1995).

The SSR analyses confirmed the utility of these markers in population studies of $H$. armigera and $H$. zea in Brazil, and presumably in South America. This is suggested by the fact that the loci did not show linkage disequilibrium, indicating that they can be used as independent genetic markers. Deviation from HWE was detected for locus HarSSR1 in the HaRS-2 population; for the same locus and population, null alleles were detected. In the other loci and populations where null alleles were detected, there were no deviations from HWE. The presence of null alleles at microsatellite loci is a major cause of deviations in HWE proportions because it confounds genotyping and leads to an accounting of more homozygotes (Chakraborty et al., 1992). Null alleles are quite common among Lepidoptera (Meglecz et al., 2004), but the lack of a high nullallele frequency and few HWE deviations suggest that they do not pose a significant problem for Helicoverpa. This may be due to the conservation of primer sites with cross-amplified loci; primers that work in both species would tend not to carry mutations that would prevent amplification and present null alleles. In general, the SSR loci evaluated showed a moderate level of polymorphism, and can be useful for simultaneous population genetic studies in $H$. armigera and $H$. zea.

$H$. armigera is an invasive pest recently reported in Brazil, which may account for the higher inbreeding coefficient in relation to $H$. zea populations. However, $H$. armigera populations showed consistently higher levels of genetic diversity, as demonstrated by the higher observed heterozygosity values than those of $H$. zea populations. Leite et al. (2014) reported similar results in $H$. armigera and $H$. zea Brazilian populations using the mitochondrial $\mathrm{CO}$ gene sequence. Three hypotheses can explain these results: first, there could be higher intrinsic genetic diversity in $H$. armigera species relative to $H$. zea, since it is hypothesized that $H$. zea populations were established via a founder event from $H$. armigera individuals on the American continent (Behere et al., 2007). Second, $H$. armigera populations may have resulted from multiple-independent introductions, with subsequent gene flow among the populations increasing their genetic diversity. Third, since more $\mathrm{H}$. armigera loci work in $H$. zea, these may evolve or mutate slower because they are more conserved. If we had more $H$. zea-specific loci, they might actually be more polymorphic in $H$. zea. Lastly, the increased genetic diversity is related to potential hybridization and introgression events between $H$. armigera and other Helicoverpa species (Laster and Hardee, 1995; Laster and Sheng, 1995). 
The genetic identity of each individual detected with the STRUCTURE analysis showed that the individuals were mostly separated into two distinct clusters $(K=2)$ according to the $H$. armigera and $H$. zea species as identified by mtDNA. However, nine $H$. armigera individuals and one $H$. zea individual, previously identified by their mitochondrial $\mathrm{COI}$ gene sequence, showed greater than $0.50(50 \%)$ genetic similarity to each other. This result suggests natural hybridization among individuals of different species, with an individual carrying a cytoplasmic genome from one species or population and a partial nuclear genome from the other species (Freeland et al., 2011). However, the SSR loci were not useful to characterize a large number of species-specific alleles, mainly for $H$. zea (see Table 3), which complicates the specific identification of hybrid individuals from interspecific crosses between $H$. armigera and $H$. zea. Further analyses and population studies using this set of microsatellites should be done on $H$. armigera and $H$. zea populations collected prior to $H$. armigera introduction in Brazil and or in the regions where these two species occur separately, to enable accurate and unambiguous differentiation between both species alleles.

We hope that the cross-species amplification and validation of the seven SRR loci from $H$. armigera and $H$. zea populations will contribute to a better understanding of the genetic structure, reproductive behavior, intra- and interspecific gene flow, and adaptation processes of these two important agricultural pests. There is a scarcity of such information, especially for populations in the Americas, where $H$. armigera and $H$. zea populations occur simultaneously in different crops and landscapes throughout the year.

\section{Conflicts of interest}

The authors declare no conflict of interest.

\section{ACKNOWLEDGMENTS}

The financial support and scholarship provided by Conselho Nacional de Desenvolvimento Científico e Tecnológico (CNPq), Fundação de Amparo à Pesquisa do Estado de São Paulo (FAPESP) (Process \#2014/11495-3), and Coordenação de Aperfeiçoamento de Pessoal de Nível Superior (CAPES) are greatly appreciated. A. Alves-Pereira thanks FAPESP for a scholarship (\#2013/11137-7). We thank Celito Breda, Pedro Matana Junior, Rogério Machado Pereira, and SGS Gravena (SISBIO License \#18018-1) for helping to collect insect samples in different Brazilian regions. We thank Prof. Andrew P. Michel for reviewing this manuscript. We also thank Prof. José Baldin Pinheiro for providing laboratory space and equipment.

\section{REFERENCES}

Behere GT, Tay WT, Russell DA, Heckel DG, et al. (2007). Mitochondrial DNA analysis of field populations of Helicoverpa armigera (Lepidoptera: Noctuidae) and of its relationship to H. zea. BMC Evol. Biol. 7: 117. http://dx.doi.org/10.1186/14712148-7-117

Behere GT, Tay WT, Russell DA and Batterham P (2008). Molecular markers to discriminate among four pest species of Helicoverpa (Lepidoptera: Noctuidae). Bull. Entomol. Res. 98: 599-603. http://dx.doi.org/10.1017/S0007485308005956

Behere GT, Tay WT, Russell DA, Kranthi KR, et al. (2013). Population genetic structure of the cotton bollworm Helicoverpa armigera (Hübner) (Lepidoptera: Noctuidae) in India as inferred from EPIC-PCR DNA markers. PLoS One 8: e53448. http://dx.doi.org/10.1371/journal.pone.0053448

Chakraborty R, De Andrade M, Daiger SP and Budowle B (1992). Apparent heterozygote deficiencies observed in DNA typing data and their implications in forensic applications. Ann. Hum. Genet. 56: 45-57. http://dx.doi.org/10.1111/j.1469-1809.1992. tb01128.x 
Chapuis MP and Estoup A (2007). Microsatellite null alleles and estimation of population differentiation. Mol. Biol. Evol. 24: 621-631. http://dx.doi.org/10.1093/molbev/msl191

Cho S, Mitchell A, Mitter C, Regier J, et al. (2008). Molecular phylogenetics of heliothine moths (Lepidoptera: Noctuidae: Heliothinae), with comments on the evolution of host range and pest status. Syst. Entomol. 33: 581-594. http://dx.doi. org/10.1111/j.1365-3113.2008.00427.x

Czepak C, Albernaz KC, Vivan LM, Guimarães HO, et al. (2013). Primeiro registro de ocorrência de Helicoverpa armigera (Hübner) (Lepidoptera: Noctuidae) no Brasil. Pesq. Agropec. Trop. 43: 110-113. http://dx.doi.org/10.1590/S1983$\underline{40632013000100015}$

Earl DA and vonHoldt BM (2012). STRUCTURE HARVESTER: a website and program for visualizing STRUCTURE output and implementing the Evanno method. Conserv. Genet. Resour. 4: 359-361. http://dx.doi.org/10.1007/s12686-011-9548-7

Endersby NM, Hoffmann AA, McKechnie SW and Weeks AR (2007). Is there genetic structure in populations of Helicoverpa armigera from Australia? Entomol. Exp. Appl. 122: 253-263. http://dx.doi.org/10.1111/j.1570-7458.2006.00515.x

Evanno G, Regnaut S and Goudet J (2005). Detecting the number of clusters of individuals using the software STRUCTURE: a simulation study. Mol. Ecol. 14: 2611-2620. http://dx.doi.org/10.1111/j.1365-294X.2005.02553.x

Fitt GP (1989). The ecology of Heliothis species in relation to agroecosystems. Annu. Rev. Entomol. 34: 17-53. http://dx.doi. org/10.1146/annurev.en.34.010189.000313

Freeland JR, Kirk H and Petersen S (2011). Molecular ecology. 2nd edn. John Wiley and Sons, Chichester.

Goudet J (2002). FSTAT, a program to estimate and test gene diversities and fixation indices, release 2. Available at [http:// www2.unil.ch/popgen/softwares/fstat.htm]. Accessed August 10, 2015.

Grasela JJ and Mclntosh AH (2005). Cross-species investigation of Helicoverpa armigera microsatellites as potential markers for other related species in the Helicoverpa - Heliothis complex. J. Insect Sci. 5: 47. http://dx.doi.org/10.1093/jis/5.1.47

Greene GL, Lepla NC and Dickerson WA (1976). Velvet bean caterpillar (Lepidoptera, Noctuidae) rearing procedure and artificial medium. J. Econ. Entomol. 69: 487-488.

Hayden JE and Brambila J (2015). Pest alert: the Old World bollworm. Available at [http://www.freshfromflorida.com/DivisionsOffices/Plant-Industry/Plant-Industry-Publications/Pest-Alerts/Pest-Alert-The-Old-World-Bollworm]. Accessed October 5, 2015.

Head G, Jackson RE, Adamczyk J, Bradley JR, et al. (2010). Spatial and temporal variability in host use by Helicoverpa zea as measured by analyses of stable carbon isotope ratios and gossypol residues. J. Appl. Ecol. 47: 583-592. http://dx.doi. org/10.1111/j.1365-2664.2010.01796.x

Jakobsson M and Rosenberg NA (2007). CLUMPP: a cluster matching and permutation program for dealing with label switching and multimodality in analysis of population structure. Bioinformatics 23: 1801-1806. http://dx.doi.org/10.1093/ bioinformatics/btm233

Ji YJ, Zhang DX, Hewitt GM, Kang L, et al. (2003). Polymorphic microsatellite loci for the cotton bollworm Helicoverpa armigera (Lepidoptera: Noctuidae) and some remarks on their isolation. Mol. Ecol. Notes 3: 102-104. http://dx.doi.org/10.1046/ j.1471-8286.2003.00366.x

Ji YJ, Wu YC and Zhang DX (2005). Novel polymorphic microsatellite markers developed in the cotton bollworm Helicoverpa armigera (Lepidoptera: Noctuidae). Insect Sci. 12: 331-334. http://dx.doi.org/10.1111/j.1005-295X.2005.00040.x

Kogan M, Helm CG, Kogan J and Brewer E (1989). Distribution and economic importance of Heliothis virescens and Helicoverpa zea in North, Central, and South America and of their natural enemies and host plants. In: Proceedings of the workshop on biological control of Heliothis: increasing effectiveness of natural enemies (King EG and Jackson RD, eds.). Far Eastern Regional Research Office, USDA, New Delhi, India, 241-297.

Laster ML and Hardee DD (1995). Intermating compatibility between North American Helicoverpa zea and Heliothis armigera (Lepidoptera: Noctuidae) from Russia. J. Econ. Entomol. 88: 77-80. http://dx.doi.org/10.1093/jee/88.1.77

Laster ML and Sheng CF (1995). Search for hybrid sterility for Helicoverpa zea in crosses between the North American $H$. zea and H. armigera (Lepidoptera: Noctuidae) from China. J. Econ. Entomol. 88: 1288-1291. http://dx.doi.org/10.1093/ jee/88.5.1288

Leite NA, Alves-Pereira A, Corrêa AS, Zucchi MI, et al. (2014). Demographics and genetic variability of the new world bollworm (Helicoverpa zea) and the old world bollworm (Helicoverpa armigera) in Brazil. PLoS One 9: e113286. http://dx.doi. org/10.1371/journal.pone.0113286

Lewis PO and Zaykin D (2001). Genetic data analysis: computer program for the analysis of allelic data. Version 1.0. Available at [http://phylogeny.uconn.edu/software/].Accessed July 15, 2015.

Li QQ, Li DY, Ye H, Liu XF, et al. (2011). Using COI gene sequence to barcode two morphologically alike species: the cotton bollworm and the oriental tobacco budworm (Lepidoptera: Noctuidae). Mol. Biol. Rep. 38: 5107-5113. http://dx.doi. org/10.1007/s11033-010-0658-1

Litt M and Luty JA (1989). A hypervariable microsatellite revealed by in vitro amplification of a dinucleotide repeat within the cardiac muscle actin gene. Am. J. Hum. Genet. 44: 397-401. 
Mastrangelo T, Paulo DF, Bergamo LW, Morais EG, et al. (2014). Detection and genetic diversity of a Heliothine invader (Lepidoptera: Noctuidae) from north and northeast of Brazil. J. Econ. Entomol. 107: 970-980. http://dx.doi.org/10.1603/ EC13403

Meglecz E, Petenian F, Danchin E, D'Acier AC, et al. (2004). High similarity between flanking regions of different microsatellites detected within each of two species of Lepidoptera: Parnassius apollo and Euphydryas aurinia. Mol. Ecol. 13: $1693-1700$. http://dx.doi.org/10.1111/j.1365-294X.2004.02163.x

Múrua MG, Scalora FS, Navarro FR, Cazado LE, et al. (2014). First record of Helicoverpa armigera (Lepidoptera: Noctuidae) in Argentina. Fla. Entomol. 97: 854-856. http://dx.doi.org/10.1653/024.097.0279

Perera OP and Blanco CA (2011). Microsatellite variation in Helicoverpa zea (Boddie) populations in the southern United States. Southwest. Entomologist 36: 271-286. http://dx.doi.org/10.3958/059.036.0305

Perera OP, Blanco CA, Scheffler BE and Abel CA (2007). Characteristics of 13 polymorphic microsatellite markers in the corn earworm, Helicoverpa zea (Lepidoptera: Noctuidae). Mol. Ecol. Notes 7: 1132-1134. http://dx.doi.org/10.1111/j.14718286.2007.01806.x

Pogue MG (2013). Revised status of Chloridea Duncan and (Westwood), 1841, for the Heliothis virescens species group (Lepidoptera: Noctuidae: Heliothinae) based on morphology and three genes. Syst. Entomol. 38: 523-542. http://dx.doi. org/10.1111/syen.12010

Pritchard JK, Stephens M and Donnelly P (2000). Inference of population structure using multilocus genotype data. Genetics 155: $945-959$.

Razmjou J, Naseri B and Hemati SA (2014). Comparative performance of the cotton bollworm, Helicoverpa armigera (Hübner) (Lepidoptera: Noctuidae) on various host plants. J. Pest Sci. 87: 29-37. http://dx.doi.org/10.1007/s10340-013-0515-9

Scott KD, Lange CL, Scott LJ and Graham GC (2004). Isolation and characterization of microsatellite loci from Helicoverpa armigera Hübner (Lepidoptera: Noctuidae). Mol. Ecol. Notes 4: 204-205. http://dx.doi.org/10.1111/j.1471$\underline{8286.2004 .00617 . x}$

Senave (2014). SENAVE reafirma su autoridad en materia fitosanitaria. Available at [http://www.senave.gov.py/noticias-85SENAVE-reafirma-su-autoridad-en-materia-fitosanitaria.html]. Accessed October 5, 2015.

Subramanian S and Mohankumar S (2006). Genetic variability of the bollworm, Helicoverpa armigera, occurring on different host plants. J. Insect Sci. 6: 1-8. http://dx.doi.org/10.1673/2006 $06 \quad 26.1$

Tautz D (1989). Hypervariability of simple sequences as a general source for polymorphic DNA markers. Nucleic Acids Res. 17: 6463-6471. http://dx.doi.org/10.1093/nar/17.16.6463

Walsh TK, Downes SJ, Gascoyne J, James W, et al. (2014). Dual Cry2Ab and Vip3A resistant strains of Helicoverpa armigera and Helicoverpa punctigera (Lepidoptera: Noctuidae); testing linkage between loci and monitoring of allele frequencies. J. Econ. Entomol. 107: 1610-1617. http://dx.doi.org/10.1603/EC13558

Weir BS (1996). Genetics data analysis II: methods for discrete population genetic data. Sinauer Associates, Sunderland.

Yang Y, Li Y and Wu Y (2013). Current status of insecticide resistance in Helicoverpa armigera after 15 years of Bt cotton planting in China. J. Econ. Entomol. 106: 375-381. http://dx.doi.org/10.1603/EC12286 